\title{
PNA-tagged Peptide Microarrays for Ratiometric Activity Detection of Cellular Protein Kinases
}

\author{
Hiromu IKeda, * Yoshihiro YaYama, * Akito Hata, ${ }^{*}$ Jumpei Kamimoto, ${ }^{*}$ Tatsuhiro Yamamoto, ${ }^{* * *}$ \\ Takeshi MorI, ${ }^{* * * \dagger}$ and Yoshiki KaTAYAMA $* * * \dagger$
}

\author{
*Department of Applied Chemistry, Kyushu University, 744 Moto-oka, Nishi, Fukuoka 819-0395, Japan \\ **Center for Future Chemistry, Kyushu University, 744 Moto-oka, Nishi, Fukuoka 819-0395, Japan \\ ***Institute of System, Information Technologies and Nanotechnologies, 203-1 Moto-oka, Nishi, \\ Fukuoka 819-0385, Japan
}

\begin{abstract}
Peptide microarrays can be used to measure the activity of multiple protein kinases (PKs), which can be used to elucidate kinomics for drug discovery and diagnosis. Here we demonstrated a new microarray for ratiometric detection of the activity of PKs using peptide nucleic acid (PNA)-tagged peptides labeled with two different fluorophores, Cy3 and Cy5. We successfully detected cellular PK activities based on ratiometry, and applied the system for evaluation of an inhibitory drug.
\end{abstract}

Keywords Protein kinase, phosphorylation, microarray, PNA, peptide, IMAC, ratiometry

(Received April 24, 2014; Accepted May 2, 2014; Published June 10, 2014)

In intercellular signaling, abnormal activation of specific protein kinases (PKs) is associated with many diseases, including cancer. ${ }^{1,2}$ Thus, an analytical technique to monitor the activity of PKs is valuable not only for elucidation of the malfunctions of cellular events but also for drug discovery. ${ }^{3,4}$ Recently, microarrays of substrate peptides of PKs have been developed to measure the activity of many kinds of intracellular PKs simultaneously. ${ }^{5-14}$ Now, several companies provide commercial peptide microarrays for the measurement of intracellular PK activity. $5,6,15-17$ In spite of their usefulness, peptide microarrays have two major disadvantages: (1) low reaction efficacy of immobilized peptides compared with solution phase reaction, and (2) difficulty in quantitative evaluation of the phosphorylation of the immobilized peptides due to the relatively wide deviation of spot size. The latter issue is a common problem for microarray technology. DNA microarrays overcome this issue by using ratiometric detection ${ }^{18,19}$ where two fluorescent colors are used to label two different samples, then the mixture of the two samples are applied to DNA microarrays to measure the ratio of the two fluorescent colors from each spot. ${ }^{20}$ The ratiometric detection enables the comparison of two samples without concern about the deviation of the spot size.

Here, we for the first time applied the ratiometric detection based on the DNA microarray for PK activity measurement. Figure 1 schematically represents our strategy. First, a fluorescence-labeled substrate peptide for a target PK is connected with a peptide nucleic acid (PNA), which functions as a tag to hybridize with a specific DNA on the microarray. The substrate peptide is encoded with 7-mer PNA and this design is applicable to different combinations of the substrate

H. I., Y. Y., and A. H. equally contributed to this work.

† To whom correspondence should be addressed.

E-mail: ykatatcm@mail.cstm.kyushu-u.ac.jp peptide and PNA. The PNA-peptide conjugate is labeled with two different colors of fluorescent groups, Cy3 or Cy5. Then each PNA-peptide is phosphorylated with a different sample. After the reaction, the two samples containing different colored PNA-peptide are mixed together and then applied to a Fe-NTA column (IMAC) ${ }^{21,22}$ to enrich the phosphorylated PNA-peptides. The enriched phosphorylated PNA-peptides are applied to the DNA microarray for hybridization to gather two kinds of the PNA-peptides in one spot. Therefore, the proposed strategy enables efficient phosphorylation reaction in homogenous solution phase as well as quantitative ratiometric detection. This strategy also allows for the determination of the absolute phosphorylation ratio of the PNA-peptide substrate by using the phosphorylated PNA-peptide labeled with another fluorophore as an internal standard spike.

First, we optimized the above mentioned procedures. For the optimization of the enrichment step, we used an equimolar mixture of phosphorylated and non-phosphorylated PNA-peptide 1 and $\mathbf{2}$ (their sequences are summarized in Table 1). We screened the washing and elution buffers to maximize the purity of the phosphorylated peptides and chose suitable buffers for washing and elution buffers as $10 \mathrm{mM}$ Tris- $\mathrm{HCl}$ ( $\mathrm{pH} 7.5)$ containing $50 \%$ acetonitrile, and $1 \%$ ammonium hydroxide containing 50\% acetonitrile, respectively. Figure 2 shows the MALDI-TOF-MS spectra of the initial and enriched solution. Phosphorylated PNA-peptide $\mathbf{2}$ was successfully enriched by the Fe-NTA column from the original mixing ratio of PNA-peptide 1 and 2 (1:1) to $1: 5$ ratio.

Then, we optimized the hybridization step of PNA-peptide on the DNA microarray for good selectivity. PNA-peptide 3 was applied to the microarrays in which six kinds of oligonucleotides, DNA 1 to 6 (DNA sequences are summarized in Table 2), were hybridized for hybridization. These DNAs were immobilized on the array surface by using dT oligomers on 5 'terminus. 


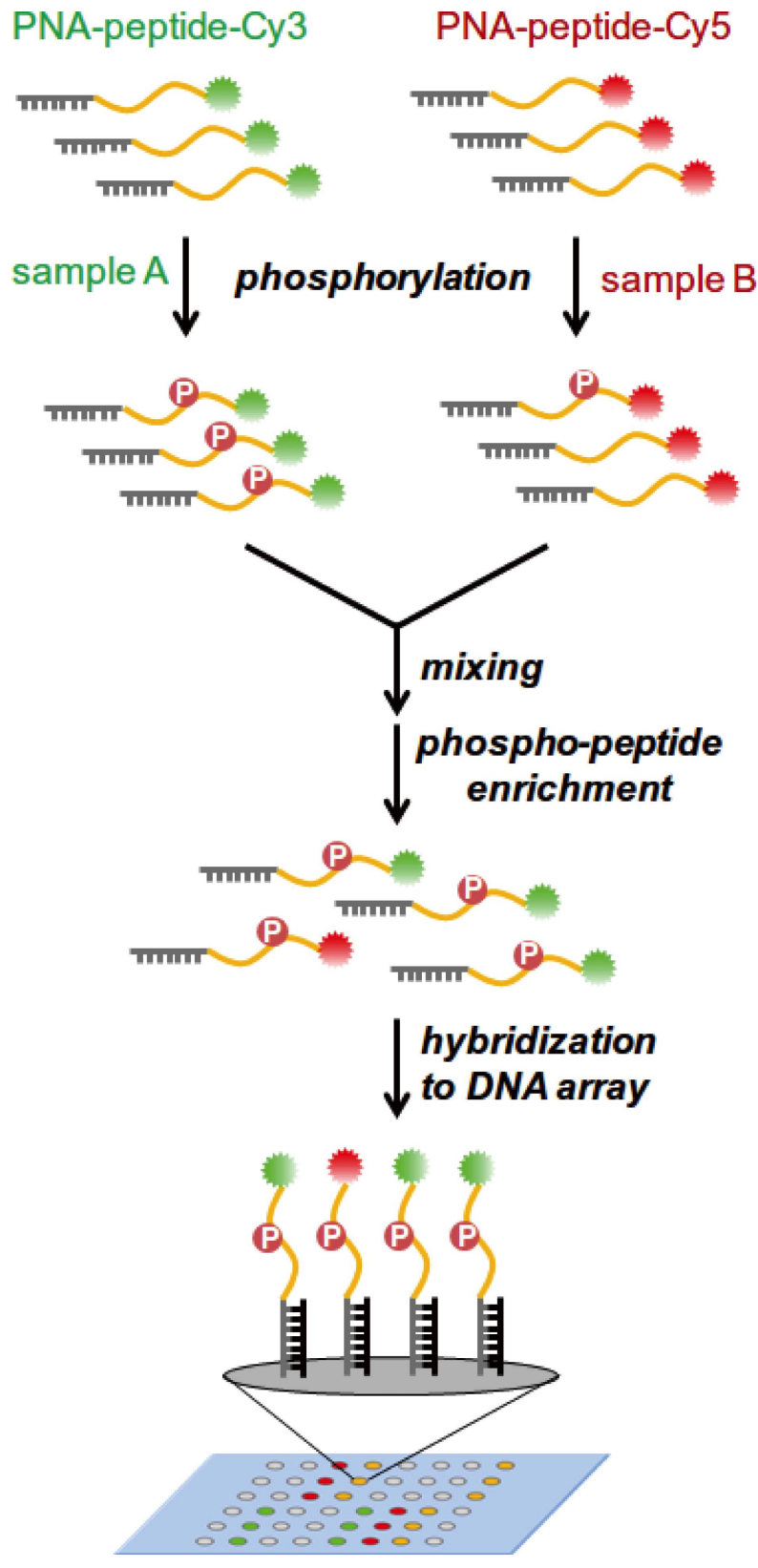

Fig. 1 Schematic illustration of PNA-tagged peptide microarray system.
Figure 3 shows the effect of $100 \mathrm{mM} \mathrm{MgCl}_{2}$ in the hybridization and the washing buffers on the selective hybridization. Interestingly, non-specific signals from other DNAs were significantly reduced but the specific signals were almost unchanged when $100-\mathrm{mM}-\mathrm{MgCl}_{2}$ was included in both hybridization and wash buffers. Being different from the DNA/DNA duplex, the stability of the PNA/DNA duplex is hardly affected by $\mathrm{Mg}^{2+} .23$ Therefore, these non-specific signals probably result from electrostatic interaction between PNA-peptides and the immobilized DNA due to the highly cationic charges of the peptide segment (net positive charge of $+5)$

We demonstrated the intracellular PK activity measurement by using the PNA-tagged peptide microarray under the optimized conditions. We used here the human hepatoma HCC827 cell line, which has relatively high $c$-Src activity. ${ }^{24}$ PNA-peptide 1, which has substrate sequence for $c$-Src, was phosphorylated by the lysate of HCC 827 (the phosphorylation ratio of PNA-peptide 1 was $80 \%$, which was confirmed by MALDI-TOF-MS analysis). The resulting phosphorylated

Table 1 Sequence of PNA-peptide

\begin{tabular}{|c|c|c|c|}
\hline $\begin{array}{l}\text { PNA- } \\
\text { peptide }\end{array}$ & Fluorophore & Substrate peptide & PNA \\
\hline 1 & TAMRA & -XEEE I Y E F D & $-\mathrm{gtcgtcg}$ \\
\hline 2 & TAMRA & -XEE E I pYGE F D X & $-\mathrm{gtcgtcg}$ \\
\hline 3 & Су3 & $-X F K Q G S$ F A K K KX & $\mathrm{X}-\mathrm{gtc}$ a a g c \\
\hline 4 & Сy5 & $-X F K Q G S F A K K K X$ & $\mathrm{X}-\mathrm{gtc}$ a a gc \\
\hline
\end{tabular}

TAMRA: tetramethylrhodamine, X: 8-amino-3,6-dioxaoctanoyl.

Table 2 Sequence of DNA

\begin{tabular}{|c|c|c|c|c|c|c|c|c|c|c|c|c|c|c|c|}
\hline DNA & & & & & & & Seq & ien & e ( & $\prime^{\prime} \rightarrow$ & & & & & \\
\hline 1 & & & & & & & & G & $\mathrm{T}$ & G & $\mathrm{G}$ & $\mathrm{T}$ & G & $\mathrm{T} \quad \mathrm{G}$ & $\mathrm{T}$ \\
\hline 2 & $\mathrm{~T}$ & $\mathrm{~T}$ & $\mathrm{~T}$ & $\mathrm{~T}$ & $\mathrm{~T}$ & $\mathrm{~T}$ & $\mathrm{~T}$ & $\mathrm{C}$ & $\mathrm{G}$ & A & $\mathrm{C}$ & G & A & $\mathrm{C}$ & \\
\hline 3 & $\mathrm{~T}$ & $\mathrm{~T}$ & $\mathrm{~T}$ & $\mathrm{~T}$ & $\mathrm{~T}$ & $\mathrm{~T}$ & $\mathrm{~T}$ & G & C & $\mathrm{T}$ & $\mathrm{T}$ & $\mathrm{C}$ & A & C & \\
\hline 4 & $\mathrm{~T}$ & $\mathrm{~T}$ & $\mathrm{~T}$ & $\mathrm{~T}$ & $\mathrm{~T}$ & $\mathrm{~T}$ & $\mathrm{~T}$ & $\mathrm{C}$ & $\mathrm{G}$ & A & $\mathrm{C}$ & $\mathrm{G}$ & $\mathrm{T}$ & A & \\
\hline 5 & $\mathrm{~T}$ & $\mathrm{~T}$ & $\mathrm{~T}$ & $\mathrm{~T}$ & $\mathrm{~T}$ & $\mathrm{~T}$ & $\mathrm{~T}$ & A & $\mathrm{T}$ & $\mathrm{G}$ & $\mathrm{C}$ & A & $\mathrm{G}$ & $\mathrm{C}$ & \\
\hline 6 & $\mathrm{~T}$ & $\mathrm{~T}$ & $\mathrm{~T}$ & $\mathrm{~T}$ & $\mathrm{~T}$ & $\mathrm{~T}$ & $\mathrm{~T}$ & $\mathrm{C}$ & A & $\mathrm{G}$ & $\mathrm{T}$ & A & $\mathrm{G}$ & $\mathrm{C}$ & \\
\hline
\end{tabular}

B

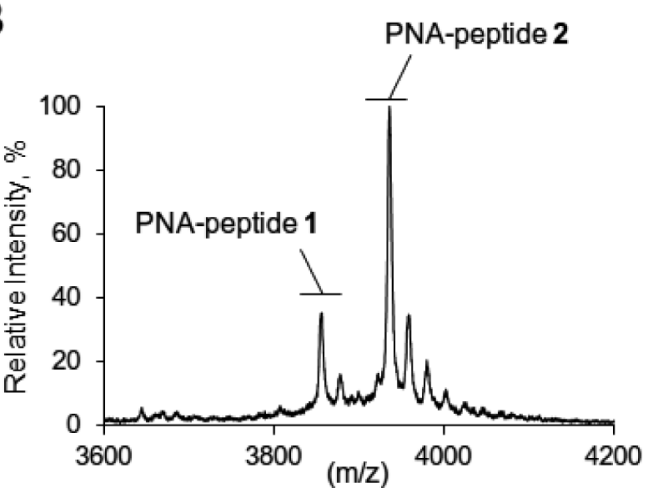

Fig. 2 Mass spectrum of PNA-peptide 1 and 2. PNA-peptide solution (PNA-peptide 1:PNA-peptide $\mathbf{2}=1: 1$ ) before (A) and after (B) enrichment by Fe-NTA column. $M_{\mathrm{W}}$ of PNA-peptide $\mathbf{1}$ and $\mathbf{2}$ were 3853.8 and 3933.8, respectively. 


\section{Condition A}
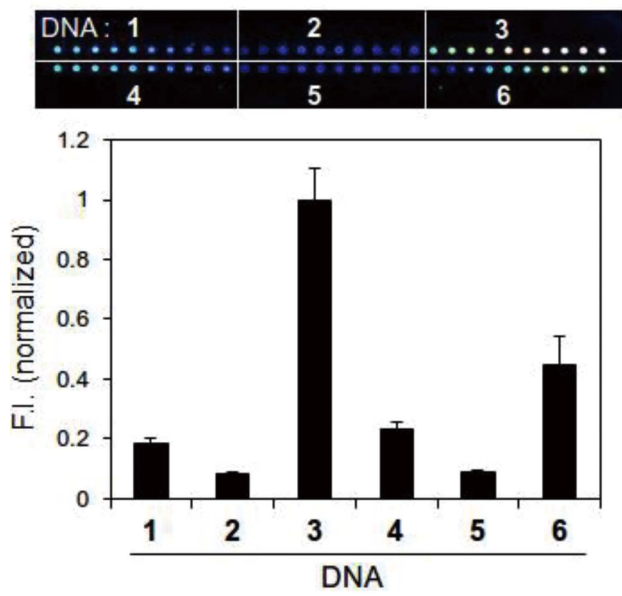

\section{Condition B}
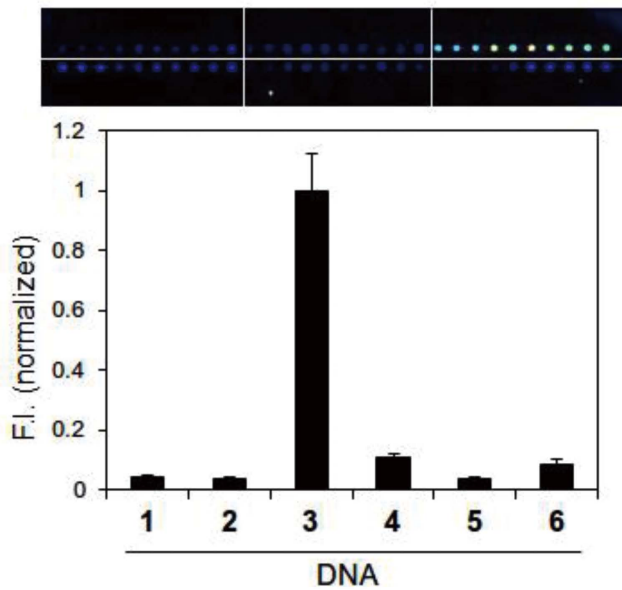

\section{Condition C}
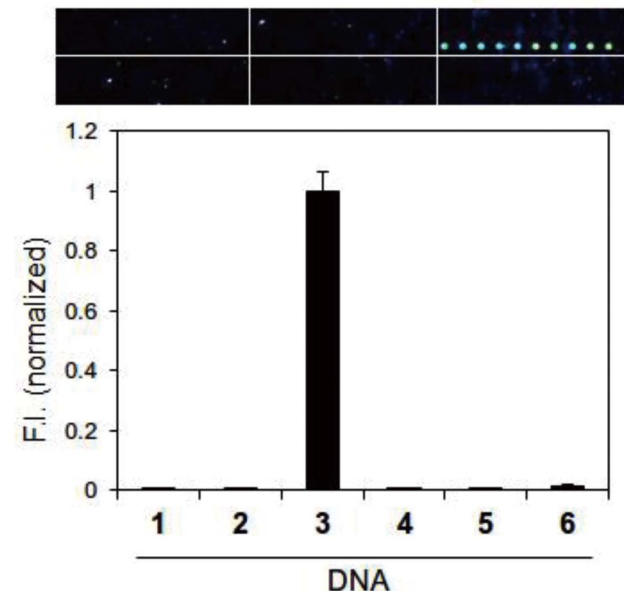

Fig. 3 Optimization of hybridization and washing buffers for the selective hybridization of PNA-peptide 3 toward immobilized DNA 3. The buffers used in conditions A - C were as follows. Condition A: hybridization buffer; TBS-T containing $0.05 \%$ Blocking One P, washing buffer; TBS-T. Condition B: hybridization buffer; TBS-T containing $0.05 \%$ Blocking One P, washing buffer; TBS-T containing $100 \mathrm{mM} \mathrm{MgCl}_{2}$.

Condition $\mathrm{C}$ : hybridization buffer; TBS-T containing $0.05 \%$ Blocking One $\mathrm{P}$ and $100 \mathrm{mM} \mathrm{MgCl}_{2}$, washing buffer; TBS-T containing $100 \mathrm{mM} \mathrm{MgCl}_{2}$.

PNA-peptide 1 was enriched by the Fe-NTA column, and then hybridized with the DNA microarray. As a negative control, the phosphorylation solution without enrichment was also placed on to the DNA microarray for the hybridization. As shown in Fig. 4B, the fluorescence signal resulting from PNA-peptide 1 was observed not only from the complementary DNA 2 but also from the non-complementary DNA 3 and 6. Meanwhile, after the enrichment by the Fe-NTA column (Fig. 4A), a strong fluorescence signal was exclusively observed from the complementary DNA 2, showing that signal-to-noise ratio was much improved after the enrichment.

Finally, we demonstrated the ratiometric detection of the inhibitory activity of a PKC $\alpha$ inhibitor by using the PNA-tagged microarray following the scheme shown in Fig. 1. We used PNA-peptide 3 and $\mathbf{4}$, which have the same substrate peptide $(\mathrm{PKC} \alpha)$ and PNA sequence but have different fluorescence groups. A PKC $\alpha$ selective inhibitor (Gö6983, $\mathrm{IC}_{50}=7 \mathrm{nM}$ ) was added to the lysate of mouse colon carcinoma cell CT-26, then PNA-peptide 3 was phosphorylated in this inhibitor-containing lysate (inhibitor conc. $=50 \mathrm{nM}$ ). Meanwhile, PNA-peptide 4 was phosphorylated in the inhibitor-free lysate. After the phosphorylation reaction, two kinds of lysates containing PNA-peptide 3 or $\mathbf{4}$ were mixed together to apply to the Fe-NTA column for enriching the phosphorylated PNA-peptides. The resulting solution which includes enriched phosphorylated peptides was applied to the DNA microarray for the hybridization. Figure 5A shows fluorescence scanning images by $\mathrm{Cy} 3$ and $\mathrm{Cy} 5$ of the DNA microarray. Both fluorescences were detected exclusively from the complementary DNA 3. Figure 5B shows the fluorescence ratio of $\mathrm{Cy} 3 / \mathrm{Cy} 5$ from DNA 3. As a control, both PNA-peptide $\mathbf{3}$ and $\mathbf{4}$ were phosphorylated in the inhibitor-free lysate and the $\mathrm{Cy} 3 / \mathrm{Cy} 5$ ratio was defined as unity. In the presence of an inhibitor, a slight decrease of the Cy3/Cy5 ratio was successfully detected. The phosphorylation ratios of PNA-peptide $\mathbf{3}$ in the inhibitor-containing and inhibitor-free lysates were determined by the MALDI-TOF-MS analysis to be 10 and $3 \%$, respectively. Thus, the ratiometric-based detection system allows for the detection of a 
A

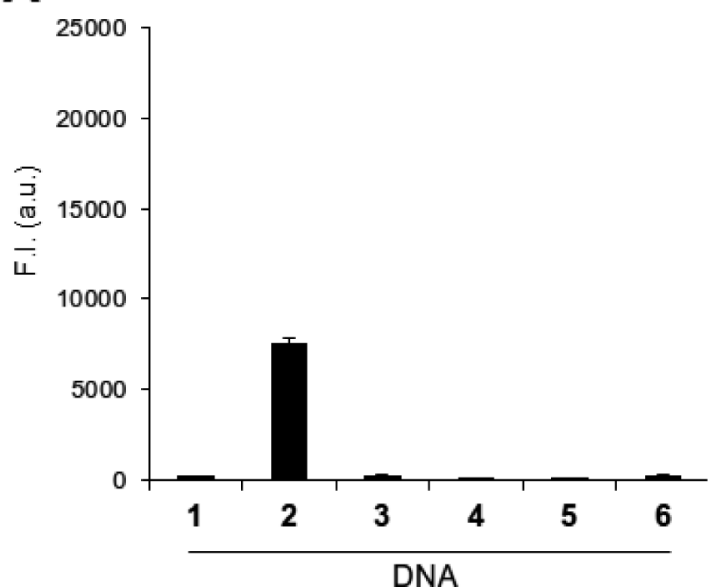

B

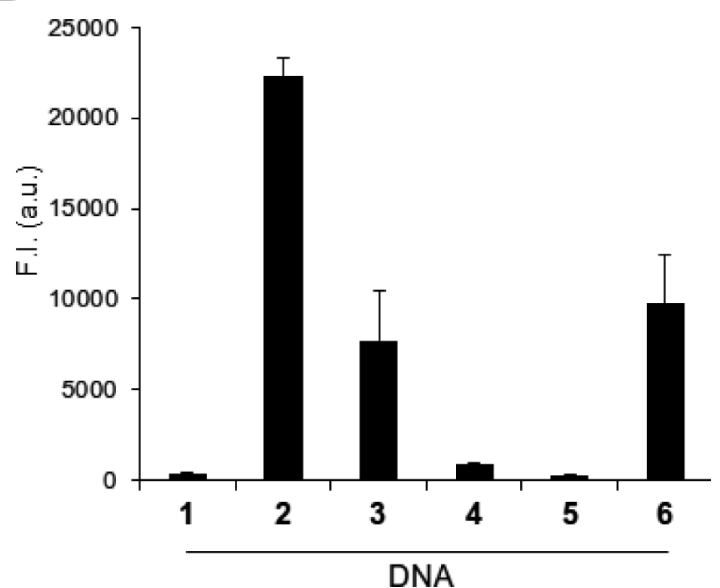

Fig. 4 Cellular $c$-Src activity measurement based on the PNA-tagged microarray. After the phosphorylation with HCC827 cell lysate, PNA-peptide 1 was enriched by Fe-NTA column then hybridized with DNA microarray (A). Results of a negative control experiment in which PNA-peptide 1 was hybridized with the DNA microarray without enrichment are shown in (B). F.I. means fluorescence intensity of each DNA spot.

A

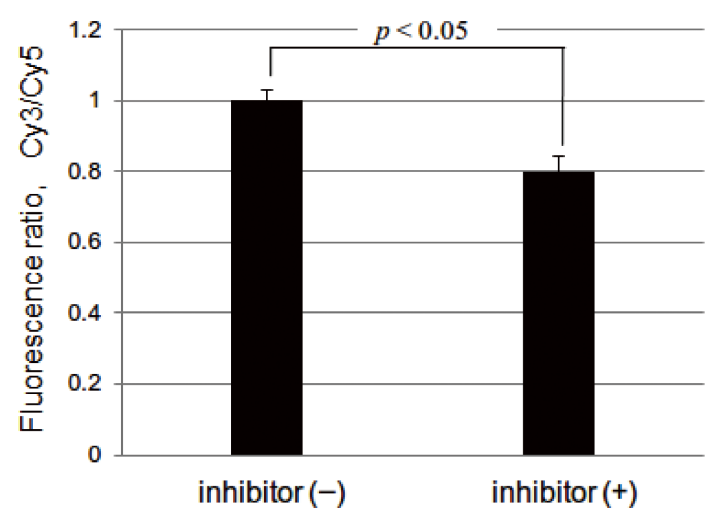

B

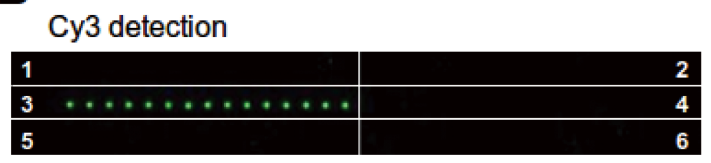

Cy5 detection

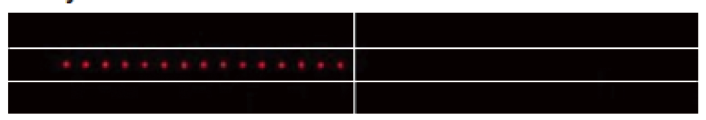

merge

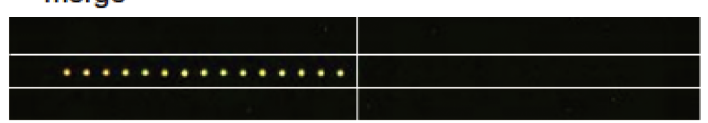

Fig. 5 Ratiometric detection of inhibition of cellular PKC $\alpha$ by using PNA-tagged peptide microarray. (A) PNA-peptide $\mathbf{3}$ and $\mathbf{4}$ were phosphorylated by CT-26 cell lysate in the presence and the absence of PKC $\alpha$-selective inhibitor, Gö6983. The Cy3 signal resulting from PNA-peptide 3 was standardized by the Cy5 signal resulting from PNA-peptide 4. (B) Fluorescent scanning images of the DNA microarrays.

decrease in phosphorylation in such a low phosphorylation range.

In conclusion, we applied ratiometric detection for the first time to the protein kinase activities measurement in which the PNA-tagged substrate peptide and the DNA microarray were used. After optimizing each process (enrichment by using a Fe-NTA column, and hybridization), we succeeded in evaluating the effect of the PKC $\alpha$ inhibitor on the cellular PKC $\alpha$ activity. Since our strategy based on ratiometric detection is principally robust and has high fidelity, it will be applicable to parallel analysis of multiple protein kinases.

\section{Acknowledgements}

This work was supported in part by the $\mathrm{P} \& \mathrm{P}$ research project of Kyushu University and by a Grant-in-Aid for Scientific Research from the Japanese Ministry of Education, Culture, Sports, Science and Technology.

\section{References}

1. T. Hunter, Cell, 2000, 100, 113.

2. G. Manning, D. B. Whyte, R. Martinez, T. Hunter, and S. Sudarsanam, Science, 2002, 298, 1912.

3. S. F. Kingsmore, Nat. Rev. Drug Discovery, 2006, 5, 310.

4. P. O. Krutzik, J. M. Crane, M. R. Clutter, and G. P. Nolan, Nat. Chem. Biol., 2008, 4, 132.

5. M. Schutkowski, U. Reineke, and U. Reimer, ChemBioChem, 2005, 6, 513.

6. R. Arsenault, P. Griebel, and S. Napper, Proteomics, 2011, $11,4595$.

7. S. H. Diks, K. Kok, T. O’Toole, D. W. Hommes, P. van Dijken, J. Joore, and M. P. Peppelenbosch, J. Biol. Chem., 2004, 279, 49206.

8. M. Jinnin, D. Medici, L. Park, N. Limaye, Y. Liu, E. Boscolo, J. Bischoff, M. Vikkula, E. Boye, and B. R. Olsen, Nat. Med., 2008, 14, 1236. 
9. A. H. Sikkema, S. H. Diks, W. F. den Dunnen, A. ter Elst, F. J. Scherpen, E. W. Hoving, R. Ruijtenbeek, P. J. Boender, R. de Wijn, W. A. Kamps, M. P. Peppelenbosch, and E. S. de Bont, Cancer Res., 2009, 69, 5987.

10. R. Hilhorst, L. Houkes, A. van den Berg, and R. Ruijtenbeek, Anal. Biochem., 2009, 387, 150.

11. K. A. Olaussen, F. Commo, M. Tailler, L. Lacroix, I. Vitale, S. Q. Raza, C. Richon, P. Dessen, V. Lazar, J. C. Soria, and G. Kroemer, Oncogene, 2009, 28, 4249.

12. T. Mori, K. Inamori, Y. Inoue, X. Han, G. Yamanouchi, T. Niidome, and Y. Katayama, Anal. Biochem., 2008, 375, 223.

13. X. Han, T. Sonoda, T. Mori, G. Yamanouchi, T. Yamaji, S. Shigaki, T. Niidome, and Y. Katayama, Comb. Chem. High Throughput Screening, 2010, 13, 777.

14. H. Ikeda, J. Kamimoto, T. Yamamoto, A. Hata, Y. Otsubo, T. Niidome, M. Fukushima, T. Mori, and Y. Katayama, Curr. Med. Chem., 2013, 20, 4419.

15. K. Parikh, M. P. Peppelenbosch, and T. Ritsema, Methods Mol. Biol., 2009, 527, 269.

16. R. Hilhorst, L. Houkes, M. Mommersteeg, J. Musch, A. van den Berg, and R. Ruijtenbeek, Methods Mol. Biol., 2013, 977, 259.

17. D. F. Winkler, K. Hilpert, O. Brandt, and R. E. Hancock, Methods Mol. Biol., 2009, 570, 157.

18. M. Schena, D. Shalon, R. W. Davis, and P. O. Brown, Science, 1995, 270, 467.

19. P. O. Brown and D. Botstein, Nat. Genet., 1999, 21, 33.

20. D. Pouchain, J. J. Díaz-Mochón, L. Bialy, and M. Bradley, ACS Chem. Biol., 2007, 2, 810.

21. D. C. Neville, C. R. Rozanas, E. M. Price, D. B. Gruis, A. S. Verkman, and R. R. Townsend, Protein Sci., 1997, 6, 2436.

22. W. Zhou, B. A. Merrick, M. G. Khaledi, and K. B. Tomer, J. Am. Soc. Mass Spectrom., 2000, 11, 273.

23. M. Egholm, O. Buchardt, L. Christensen, C. Behrens, S. M. Freier, D. A. Driver, R. H. Berg, S. K. Kim, B. Norden, and P. E. Nielsen, Nature, 1993, 365, 566.

24. J. Zhang, S. Kalyankrishna, M. Wislez, N. Thilaganathan, B. Saigal, W. Wei, L. Ma, I. I. Wistuba, F. M. Johnson, and J. M. Kurie, Am. J. Pathol., 2007, 170, 366. 